\title{
Papuloerythroderma of Ofuji in a 41-year-old woman
}

\author{
Agnieszka Terlikowska-Brzósko, Elwira Paluchowska, Witold Owczarek, Sebastian Majewski
}

Department of Dermatology, Military Institute of Medicine, Warsaw, Poland

Head of Department: Prof. Witold Owczarek MD, PhD

Postep Derm Alergol 2013; XXX, 5: 324-328

DOI: $10.5114 / p d i a .2013 .38364$

\begin{abstract}
Papuloerythroderma, described by Ofuji in 1984, is characterized by the occurrence of polygonal, erythematous-brown papules, covering the entire skin surface, except skin folds; these changes are accompanied by pruritus and eosinophilia. We report a case of a 41-year-old female patient with melanoerythroderma that has been intensifying since August 2010. The patient's personal and family history for atopy were negative. No triggering factors were identified in the course of hospitalizations. Preceding infections and neoplasms were excluded. The diagnosis of papuloerythroderma of Ofuji was established on the basis of major and minor criteria proposed by Torchia et al. The patient met all the five major criteria: 1) erythroderma-like eruption formed by coalescence of flat-topped, red-to-brown papules with a cobblestone-like appearance, 2) itch, 3) sparing of skin folds and creases, 4) histopathological exclusion of cutaneous lymphoma and other skin diseases, 5) absence of the causative factors such as tumors, infections, drugs and atopy. Regarding the 5 minor criteria, the patient met the following three: 1) peripheral (33.8\%) and tissue eosinophil$\mathrm{ia}, 2)$ elevated level of the total serum IgE (10935 IU/ml), 3) lymphopenia (6.6\%). The patient went into remission after 9-month treatment with cyclosporine at a dose of $3 \mathrm{mg} / \mathrm{kg}$.
\end{abstract}

Key words: deck-chair sign, erythroderma, itchy papules, melanoerythroderma, papuloerythroderma.

\section{Introduction}

Papuloerythroderma was described for the first time by Ofuji in 1984 [1]. In 2010, Torchia et al. carried out a metaanalysis of 170 cases of this syndrome, described until 2009 [2]. Based on their observations, the authors made an etiological division of the disease into 4 forms: 1. Primary (idiopathic); 2. Secondary (in the course of atopic disease, neoplasms, infections, drugs); 3. Papuloerythroderma imitating lymphoma; 4. Other diseases with a clinical picture similar to that of papuloerythroderma (erythroderma without papules).

Regarding the syndrome, the authors defined 10 diagnostic criteria. Five major criteria included: 1. Erythrodermic eruption, consisting of flat-topped, coalescent, redbrown papules with a cobblestone-like appearance. 2. Sparing of skin folds. 3. Pruritus. 4. Histopathological picture excluding lymphoma and other skin diseases. 5. Absence of triggering factors, such as neoplasms, infections, pharmacological agents, atopy. Minor criteria included: 1. Age over 55 years. 2. Male sex. 3. Peripheral and/or tissue eosinophilia. 4. Elevated level of total IgE. 5. Peripheral lymphopenia.
The diagnosis of the idiopathic form of the syndrome requires the presence of all the 5 major criteria [2].

\section{Case report}

A female, 41 years old, an office worker, with negative personal and family history of atopy and any chronic diseases, negated prolonged use of any medical agents and sensitization to drugs and other substances. The first skin changes occurred on the patient's trunk as erythematous papules in August 2010, accompanied by pruritus. The patient was hospitalized for progression of the skin changes. Laboratory tests revealed: an elevated level of total immunoglobulin lgE - $1415 \mathrm{IU} / \mathrm{ml}$, eosinophilia - 14\% and lymphopenia - $14 \%$. Syphilis was excluded. X-ray examination of the chest was within normal limits. An unclear clinical picture was the reason for 2 skin biopsies. The results of histopathological evaluation did not provide any unequivocal diagnosis - interface dermatitis. Systemic and local steroid therapy led to a slight transient improvement. The changes recurred soon as numerous, coalescent erythematous papules on the trunk and the limbs, with blis-

Address for correspondence: Agnieszka Terlikowska-Brzósko MD, Department of Dermatology, Military Institute of Medicine, 128 Szaserów St, 04-141 Warsaw, Poland, phone: +48 2268162 41, fax: +48 2281055 20, mobile: +48 600170658 ,

e-mail: aterlikowska-brzosko@wim.mil.pl

Received: 19.11.2012, accepted: 10.02.2013. 
tering reaction and desquamation on the feet and hands, with sparing of the nails. Peripheral lymphadenopathy and itching were present. During following hospitalizations, diagnostic procedures towards chronic infective and neoplastic processes were carried out. Eosinophilia - 33.8\%, lymphopenia $-6.6 \%$, elevated total levels of immunoglobulins: lgE $-10935 \mathrm{lU} / \mathrm{ml}$ and $\mathrm{lgA}-657 \mathrm{mg} / \mathrm{dl}$ were present. The levels of IgG, IgM and IgD immunoglobulins were normal. Taking into account the monoclonal peak of $\boldsymbol{\gamma}$-globulins, as observed in the proteinogram, diagnostic procedures were carried out towards monoclonal growths and no evident pathology was found. The endocrine basis of melanoerythroderma was excluded. No immunological exponents of infections with the following viruses: Epstein-Barr virus (EBV), cytomegalovirus (CMV), hepatitis $B$ virus (HBV), hepatitis C virus (HCV), human immunodeficiency virus (HIV) and influenza of type A and B were found. Toxoplasmosis was excluded. No signs of hyperplastic processes were demonstrated in sonographic images of either the breasts or the urogenital organs. The results of gastroscopy and colonoscopy were within normal limits. No metabolically active hyperplastic disease was identified in positron emission tomography (PET) examination. At that time, recurrent fevers and general weakness observed in the patient were the reasons for echocardiogram to exclude infectious endocarditis but the results were normal. ANA and dsDNA were absent in the serum. The persistent eosinophilia was the reason for hematological con- sultation with a subsequent bone marrow biopsy. It was consistent with reactive eosinophilia. The patient was consulted by a stomatologist, laryngologist and gynecologist and no infection foci were found. Topical treatment with anti-inflammatory and desquamative ointments was used, together with psoralen ultra-violet A (PUVA)-soak therapy for hands and feet. However, after the $4^{\text {th }}$ irradiation $\left(7.5 \mathrm{~J} / \mathrm{cm}^{2}\right.$ total dose), the therapy was discontinued for erysipelas of the left foot. Clindamycin treatment was applied. A chronic, suppressive therapy with acyclovir was started because of recurrent episodes of herpetic eczema. Papular changes further intensified, thickening of the skin and melanoderma developed accompanied by considerable pruritus. The clinical picture strongly suggested primary lymphoma of the skin (Figures 1 and 2). For that reason, skin and lymph node biopsies for histopathological examination were performed. Histopathological results of the skin revealed abundant inflammatory infiltrates of lymphocytes, plasmatic cells and eosinophilic granulocytes around small vessels and skin appendages (Figures 3 and 4). Lack of evident epidermotropism (Figures 3 and 5). On the basis of the lymph node histopathological examination, the diagnosis of dermatopathic lymphadenopathy was obtained. The PUVA irradiations were initiated and continued 3 times a week. After 5 sessions $\left(4.1 \mathrm{~J} / \mathrm{cm}^{2}\right.$ total dose), the irradiations were discontinued for recurrent exacerbations of the skin changes, with features of bacterial superinfection, especially on hands. Ther-
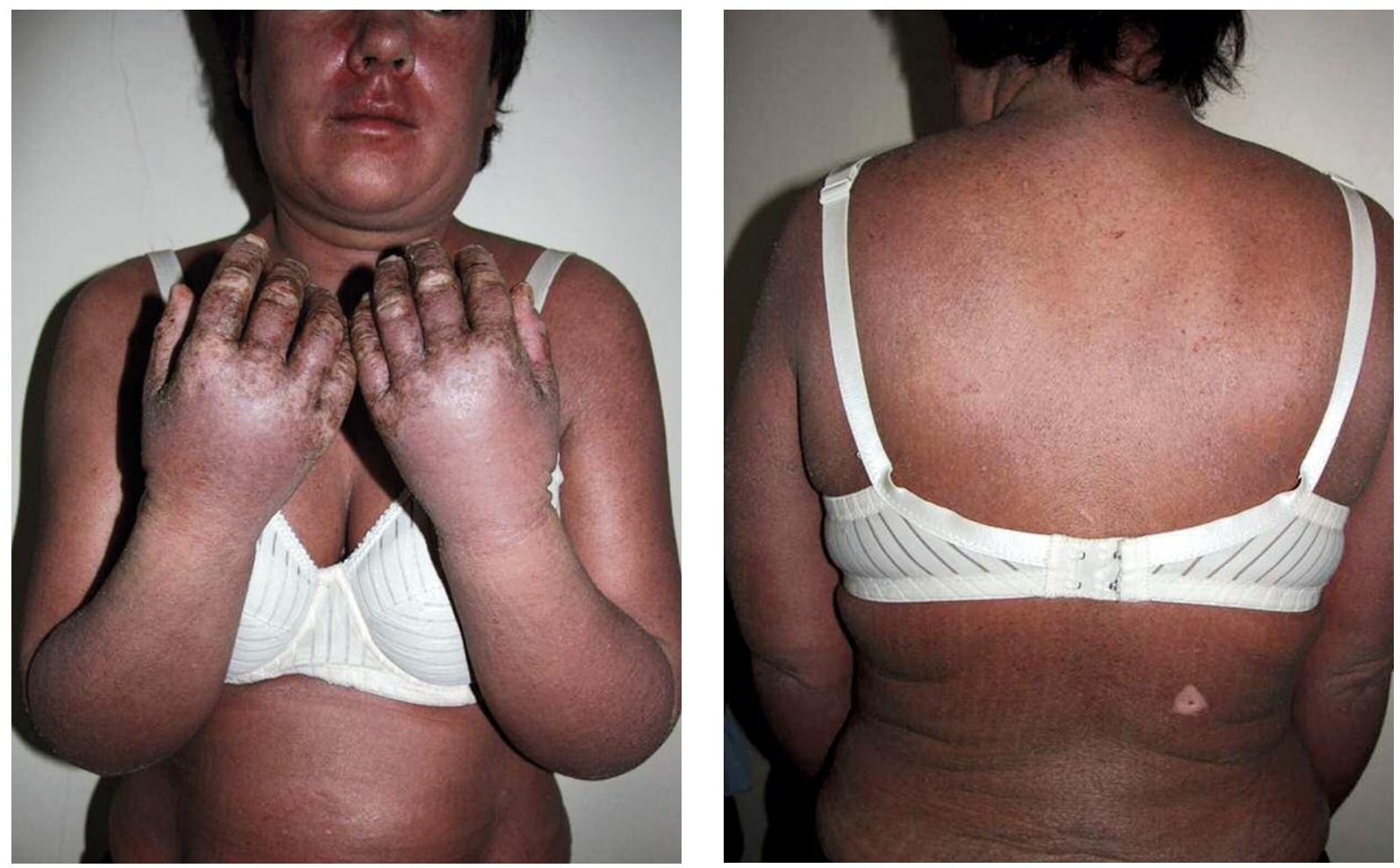

Figure 1. Melanoerythroderma. Edema and infiltration of the skin clearly visible on the hands and face 

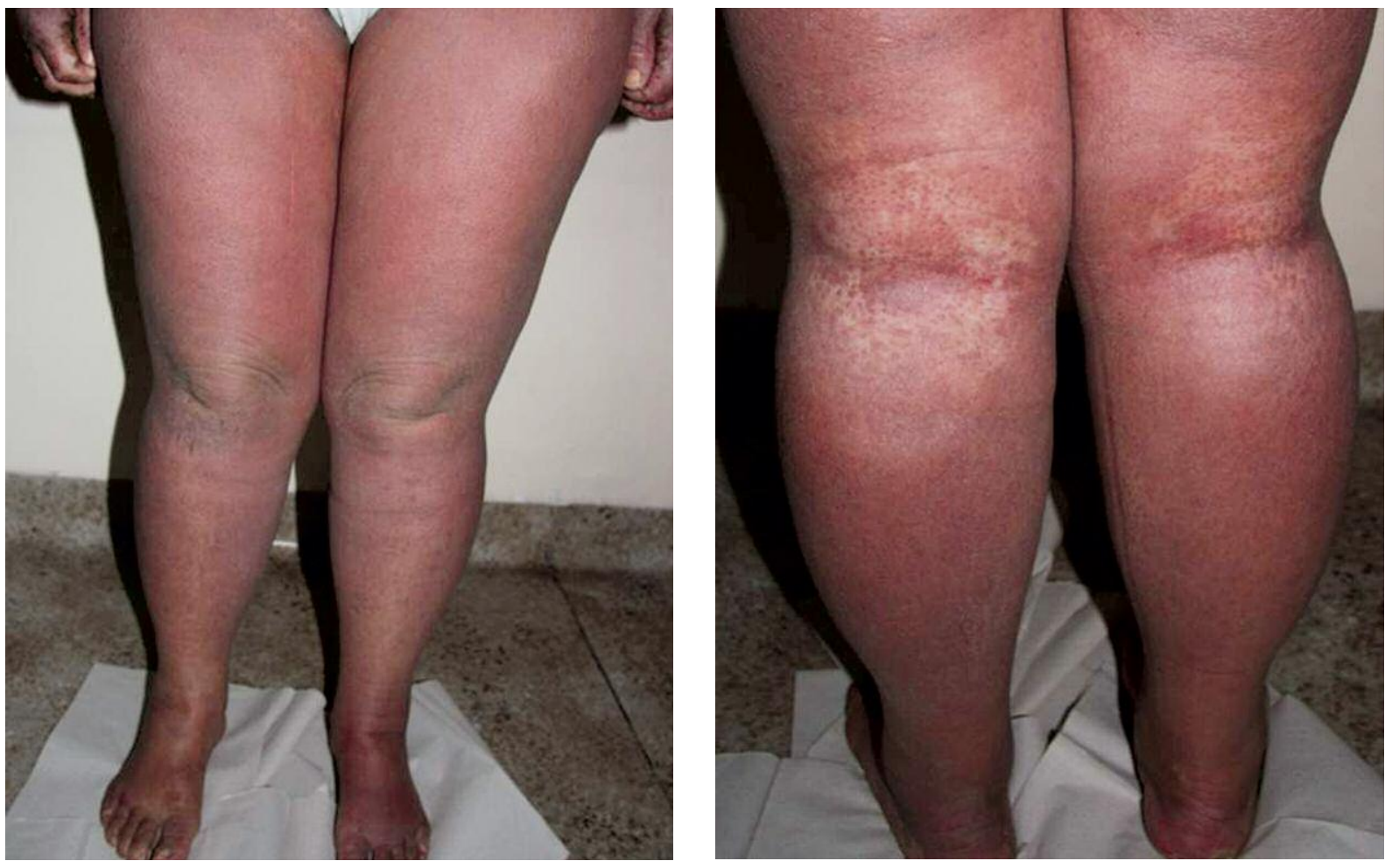

Figure 2. Edema of lower extremities. Parts of the skin without lesions in the popliteal area (deck-chair sign)

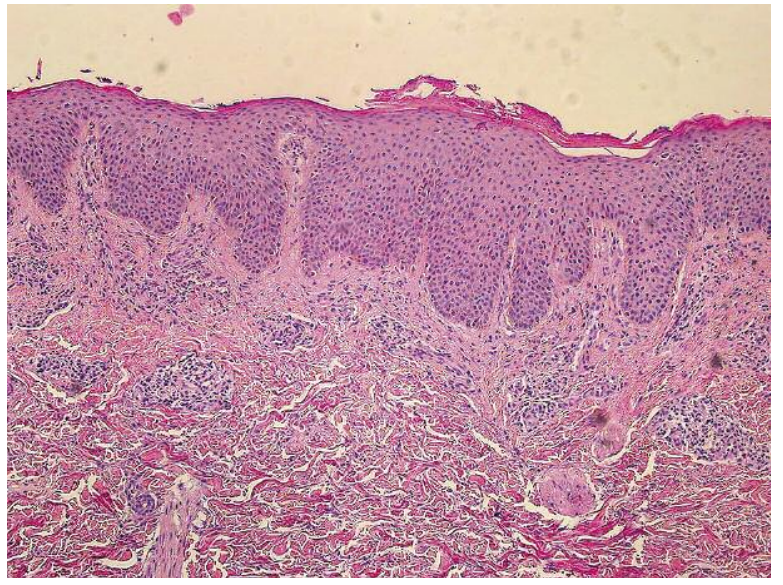

Figure 3. Focal hyperkeratosis. Epidermal acanthotic hyperplasia with minimal spongiosis. Single lymphocytes present in the epidermis. In the dermis, inflammatory infiltrates located around vessels and appendages

apy with cefuroxime was introduced. In February and March 2011, many episodes of dermatitis with local panniculitis were observed, in different localizations and with large lymphatic reactions with concomitant fever, elevated inflammatory parameters and eosinophilia. The changes resolved after antibiotic therapy. Moreover, recurrent infections of the urinary system and upper respiratory tract

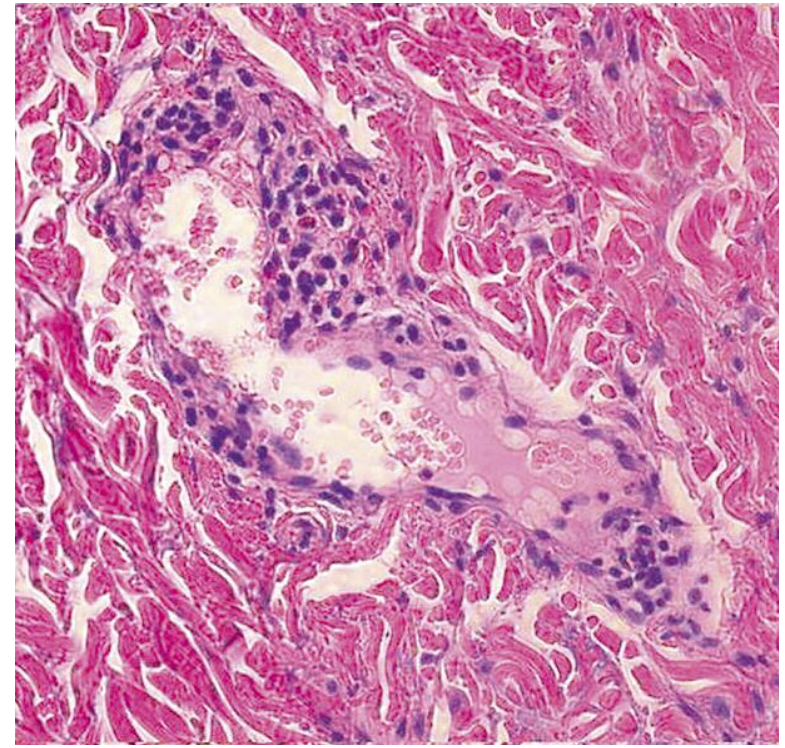

Figure 4. Lymphocytes, plasmatic cells and eosinophilic granulocytes around a vessel

were observed. Persistent melanoerythroderma, peripheral lymphadenopathy and severe pruritus were the reason for initiation of therapy with cyclosporine at $3 \mathrm{mg} / \mathrm{kg}$ in April 2011. The therapy was continued for 9 months. Melanoerythroderma subsided leaving some post-inflam- 
matory hyper- and hypopigmentation (Figure 5). In the course of the subsequent hospitalizations (August 2011, April 2012) a gradual normalization of inflammatory parameters as well as of lymphocytes and eosinophils levels was observed. Immune disorders also normalized with a maintained high level of total lgE at $888 \mathrm{lU} / \mathrm{ml}$ (April 2012). The patient has been under the medical care of the Outpatient Clinic of Dermatology Department. Neither recurrence of skin lesions nor fever episodes have been observed until September 2012, after cessation of cyclosporine therapy in January 2012.

\section{Discussion}

Papuloerythroderma of Ofuji is a rarely diagnosed syndrome of not yet entirely understood etiopathogenesis. After analysis of 170 cases of papuloerythroderma of Ofuji, Torchia et al. noted that most of the patients were elderly men [2]. Itchy skin changes occurred on the trunk and limbs, sparing the appendages and mucous membranes. No signs of the characteristic, monomorphic eruption, consisting of coalescent, flat-topped, red-brown papules, were found on skin folds (deck-chair sign). On average, 7 months passed from eruption occurrence to diagnosis. Histopathological examination of the skin material was not characteristic. Hyperkeratosis, acanthosis and spongiosis were observed in the epidermis, while in the dermis the inflammatory infiltration around vessels consisted mostly of lymphocytes, histiocytes and eosinophils. In some patients, the authors described preceding diseases. In 37 cases, neoplasms were identified, including 15 cases of gastric cancer, 4 lymphomas, 4 leukemias, 3 colon carcinomas, 2 prostate cancers and single cases of other neoplasms [2]. Moreover, bacterial, viral and fungal infections were also described as triggering factors. Medical agents most often suspected to induce the discussed syndrome included isoniazid, etretinate, furosemide [3], ranitidine [4], aspirin [5] and ticlopidine [2]. Based on those observations, the researchers made the disease a subject of classification and defined 10 diagnostic criteria [2], see the Introduction above. The reported patient met all the major criteria. Numerous episodes of acute viral and bacterial infections of the skin, the respiratory tract and the urinary system, not observed before the onset of the disease, worsened the course of the syndrome. Out of the minor criteria, the patient demonstrated an increased level of total IgE, lymphopenia and serum and tissue eosinophilia. The patient did not meet the criteria of sex and age. In the case of the described patient, the diagnosis of idiopathic Ofuji syndrome (5 major and 3 minor Torchia's criteria) was obtained not before as many as 9 months of diagnostic procedures. The initially applied steroid therapy, local and general, as well as photochemotherapy turned out ineffective. A clinical improvement with subsequent remission of skin changes was achieved after cyclosporine A administration, started from a dose of $3 \mathrm{mg} / \mathrm{kg}$ b.w. and con-

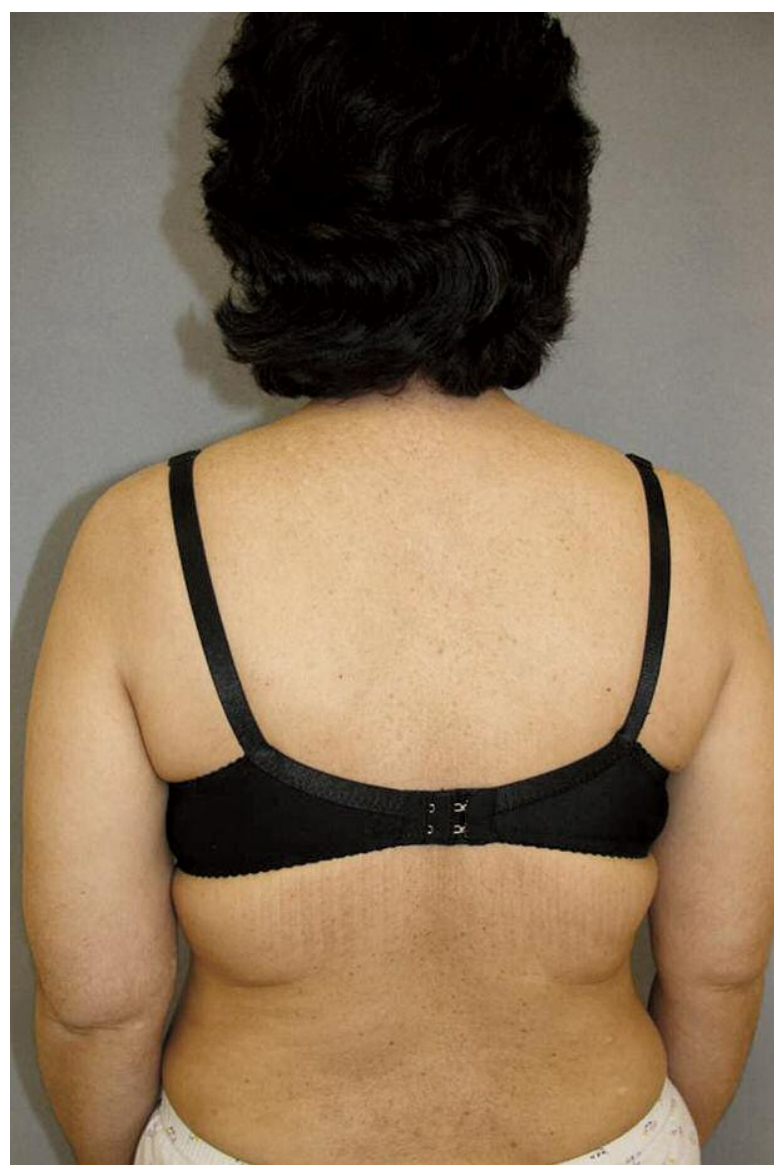

Figure 5. Regression of melanoerythroderma after 9 months' therapy with cyclosporine. Hypertrichosis

tinued for 9 months. There are no standards for the pharmacological therapy of the Ofuji syndrome. Local and/or systemic corticosteroids are most frequently used, both alone and combined with antihistaminic drugs, as well as various forms of phototherapy and photochemotherapy, also in combination with retinoids and etretinate in monotherapy [6, 7]. Good effects after treatment with cyclosporine were described [8]. Interferon $\alpha$ [9] and azathioprine [10] were also tried. The therapeutic effect depends on concomitant diseases. In 2012, Teraki, Aso and Sato described 11 cases of papuloerythroderma, out of which, 6 had neoplasms, including 4 gastric cancers [11]. In some of those patients, either remission or temporary improvement was achieved after a successful treatment of the concomitant tumor. Fairly interesting is the authors' observation that skin changes had preceded neoplastic formation in all 6 cases. An assumption may then be considered that, at least in some patients, papuloerythroderma of Ofuji is a paraneoplastic syndrome [12]. The case of a 75year-old Japanese male patient may confirm this thesis as papuloerythroderma of Ofuji coexisted in that patient with skin changes, typical of paraneoplastic acrokeratosis (Bazex syndrome), prior to the later obtained diagnosis 
of hepatic cancer [13]. In a 74-year-old man, in whom papuloerythroderma recessed after local glucocorticoid administration in occlusion, chronic lymphatic leukemia of type B was identified [14]. In an 85-year-old woman, 7 years after a successful treatment of papuloerythroderma with systemic and local steroids, a T-cellular lymphoma developed [15].

These examples suggest a higher risk of malignancy in patients with papuloerythroderma comparing to the average population. Taking into account the possibility of neoplastic developments, patients with papuloerythroderma of Ofuji require periodical control examinations, even after recession of active skin changes.

\section{References}

1. Ofuji S, Furukawa F, Miyachi Y, et al. Papuloerythroderma. Dermatologica 1984; 169: 125-30.

2. Torchia D, Miteva M, Hu S, et al. Papuloerythroderma 2009: two new cases and systematic review of the worldwide literature 25 years after its identification by Ofuji et al. Dermatology 2010; 220: 311-20.

3. Sugita K, Kabashima K, Nakashima D, et al. Papuloerythroderma of Ofuji induced by furosemide. J Am Acad Dermatol 2008; 58 (Suppl.): S54-5.

4. Fujii K. Ranitidine-induced drug eruption: another case of papuloerythroderma? J Dermatol 2007; 34: 736.

5. Sugita K, Tokura Y. Drug-induced papuloerythroderma of Ofuji: comment. J Dermatol 2008; 35: 377.

6. Mutluer S, Yerebakan O, Alpsoy E, et al. Treatment of papuloerythroderma of Ofuji with re-PUVA: a case report and review of the therapy. J Eur Acad Dermatol Venereol 2004; 18: 480-3.

7. Fujii K, Kanno Y, Ohgo N. Etretinate therapy for papuloerythroderma. Eur J Dermatol 1999; 9: 610-3.

8. Sommer S, Henderson CA. Papuloerythroderma of Ofuji responding to treatment with Cyclosporin. Clin Exp Dermatol 2000; 25: 293-5.

9. Plantin P, Milochau P, Leroy JP, et al. Ofuji's papuloerythroderma: efficacy of interferon-alpha. Ann Dermatol Venereol 1992; 119: 643-5.

10. Quéméneur T, Ghislain PD, Morant C, et al. Ofuji's papuloerythroderma: two cases treated with azathioprine. Ann Dermatol Venereol 2002; 129: 213-5.

11. Teraki Y, Aso Y, Sato Y. High incidence of internal malignancy in papuloerythroderma of Ofuji: a case series from Japan. Dermatology 2012; 224: 5-9.

12. Guisado Vasco P, Fraile Rodrigez G, Barbolla Diaz I, et al. Comments on: Papuloerythroderma of Ofuji associated with chronic lymphatic leukaemia (Eur J Dermatol 2009; 19: 396-7). Eur J Dermatol 2010; 20: 418.

13. Goto H, Hara H, Takayanagi T, et al. Coexistence of papuloerythroderma of Ofuji and acrokeratosis paraneoplastica (Bazex syndrome) preceding the diagnosis of primary hepatocellular carcinoma. Int I Dermatol 2011; 50: 1393-6.

14. Salguero I, Moreno C, Aguayo-Leiva I, et al. Papuloerythroderma of Ofuji associated with chronic lymphatic leukaemia. Eur J Dermatol 2009; 19: 396-7.

15. Martinez-Barranca ML, Munoz-Perez MA, Garcia-Morales I, et al. Ofuji papuloerythroderma evolving to cutaneous T-cell lymphoma. J Eur A Dermatol Venerol 2005; 19: 104-6. 